\title{
The Development Process PLC Competencies for School Administrators in Buriram Province
}

\author{
Kovit Vajarintarangoon ${ }^{1}$, Phaophongphat Bunkanan ${ }^{1}$, Sittichai Deelon ${ }^{1}$, Sripen Poldech ${ }^{1} \&$ Kittiwat Thauyngam ${ }^{1}$ \\ ${ }^{1}$ Department of Educational Foundation, Faculty of Educaiton, Buriram Rajabhat University, Thailand \\ Correspondence: Kovit Vajarintarangoon, Department of Educational Foundation, Faculty of Educaiton, Buriram \\ Rajabhat University, Thailand.
}

Received: November 23, 2018

doi:10.5539/ies.v12n6p148
Accepted: January 8, 2019 Online Published: May 29, 2019

URL: https://doi.org/10.5539/ies.v12n6p148

\begin{abstract}
The purposes of the research study were to a) study the current situation of school management and administration using professional learning community b) to develop professional learning community for the school administrators and c) follow up collaborative practice among school colleagues and administrators within school using professional learning community in Buriram Province. The researcher utilized focused interview sessions, group interview questionnaires, and Professional Learning observation within school to determine how the school colleagues perceived the implementation of professional learning communities. The results indicated that: 1) A school's PLC isn't working, common problems in Buriram Province include: a) Personal practice, b) Insufficient collaborative work, 3) Academics support, and 4) supportive conditions. 2) School administrators' competencies development after implementation of PLC workshop have an influence on process of using PLC in school. School administrators' competencies included supportive conditions for safe environment of PLC, creating environment that support learning collaboratively and respect for individual differences and developing collegial relationships for planning, following up of supervision process through action planning that support collaborative work among school colleagues. 3) Model of school administrators' competencies development in Buriram Province were a) a PDCA model incorporated with contemplative education that driven through small group of PLCs. This model utilized school administrators as coach and mentor to reflect on co-operation of group problem solving in the same group c) a PLC comprised of school teachers, coming together by grade level, content area, or through an interdisciplinary group. The purpose of a PLC was to build a community of teachers to focus on a common goal or objective collaboratively.
\end{abstract}

Keywords: competencies development, process of PLC, professional learning community, school administrator

\section{Introduction}

Policy of the minister of education, fiscal year 2560, the development of teachers to improve the quality of learning fellow the guidelines of the king's philosophy by active learning and Professional Learning Community (PLC) to quality of Thailand 4.0. The process of teacher development by using school based of aggregation, mind, force, teachers collaboration, administrators and students to develop learning of child centered and not to add to the burden on teachers and be not too much to take the PLC training time. The ministry of education provided teachers that can lead the PLC training hours to combine with the number of hours taught. The book will be used as a basis for academic advancement following the new guidelines will be published.

The success of the professional learning community consisted of many factors to be recommended to personnel for understanding and accepting first such as accepting that the heart of the teacher's learning was students' learning and teaching/teacher performance affected student learning, understanding the difference in learning levels, creating a collaborative atmosphere, building a good relationship, listening and commenting with a positive attitude and royal thought (King Rama IX) consisted of social environment, participation, public benefit, holistic, following the hierarchy, being self-reliant and being save and simple to be maximum benefit. The Professional Learning Community (PLC) was a process of creating change by learning from it (Lunenburg, 2010). It worked on a group of people who came to work together and support each other, the purpose was to improve the learner's learning and put together the learning goals of the learner and examine, It reflected on individual performance and overall outcomes through a learning process, criticism, collaboration by focusing on and promoting a holistic learning process (Luis \& Kruse, 1995). There were at least 5 issues were a) having a common goal in learning 
management/developed the learner to the fullest potential. b) exchanged of learning from the site/ actual situation of the class c) involved for all parties/ supported the change in the target. d) reflected on the learners' performance and f) HOPE was created for the team such as (a) honesty \& humanity, (b)option \& openness , (c) patience \& persistence and (d) efficacy \& enthusiasm (Chaichaorat, 2015).

Competencies Development that made Professional Learning Community: PLC, it must consist of a members of a group of people mentioned above. The integration of community members to professional learning also required the key features produced a wide range of PLCs for 5 items that were a) shared values and vision, b) collective responsibility for students learning, c) reflective professional inquiry, d) collaboration and f) supportive conditions structural arrangements and collegial relationships) (Hord, Roussin, \& Sommers, 2009).

Therefore; the researchers saw the necessity of driving the policy under the project of "PLC driven to improve learner quality Thailand 4.0". The goal was to educate understanding for the involved persons were the administrators, teachers and educational personnel of the Education Service Area Office. The PLC: Professional Learning Community process could be implemented in a systematic and continuous way. The PLC was monitored to assist the PLC's operations. Thailand 4.0 was a reflection of the performance of PLC to build a culture of learning organization.

\subsection{The Purpose of Research}

1) To study the PLC process problems of educational institutes in Buriram Province.

2) To develop PLC performance for school administrators in Buriram Province.

3) To achieve the PLC process development model for school administrators Buriram Province.

\subsection{The Importance of Research}

1) Administrators, teachers from all schools and educational personnel in Buriram Province who developed and brought knowledge to drive PLC activities in schools and agencies.

2) Buriram Educational Service Area Office PLC-driven model of real-world school.

\subsection{Research Scope}

This research that researchers have defined the scope of research as follows:

1) There were 24 schools in the Buriram Educational Service Area Office.

2) The target group in this research was the school administrators, deputy directors who volunteered to participate in the project for 24 schools.

3) Duration of research in this research, the research duration was 1 year.

\section{Method}

This research was Research and Development (R\&D), the process of conducting research and the research methodology was as follows.

\subsection{Phrase 1 Basic Data Analysis}

The researchers collected data on analyzing educational policy data, key performance indicators for academic administrators and basic information on PLC development process of the administrators of Buriram Province.

\subsection{Phrase 2 Development Design}

Basic data analysis and researchers target what the expectations were as follows.

1) Preparing a draft PLC performance improvement for school administrators and the tools.

2) Interviewing the relevant people and experts.

3) Implementing PLC process improvement

Once completed, you will be able to develop a competency development plan for the PLC Training Kit and expertly collected data collection tools that can be used with quality.

\subsection{Phrase 3 Implementation}

Implementing PLC based community-based learning is driven by a workshop. The researchers and lecturers trained the school administrators for 2 days.

The result is that the administrators of Buriram Provincial Education Office have developed the capacity of PLC. 


\subsection{Phrase 4 Evaluation}

Researchers supervised and evaluate of PLC Process Improvement for school Administrators in Buriram Province. It could be summary of research results and reports.

\subsection{Data Collection}

In this data collection, the researchers collected by:

1) The researchers made the target school books to ask for cooperation to participate in the research.

2) Making guest speaker invitations.

3) Organizing the PLC training for school administrators for 2 days.

4) Following the development of PLC processes for school administrators and assessing the performance.

2.6 Data Analysis

Data analysis in this research followed these steps as follows:

1) Questionnaire which researchers used content analysis methods.

2) The consistency of content that experts agreed in the same direction.

3) Research used qualitative research by content analysis documentation and used evidences from subgroup meetings, questionnaires, observations, informational systems and interpretations to find PLC models. It could be used to analyze the performance of the PLC process, evaluate the understanding and development of the work pieces and the workload assigned then summarized and wrote a descriptive report.

\section{Results}

The research on the development of PLC performance for educational administrators in Buriram Province, the results of the research were as follows.

\subsection{A study of PLC Process Problems of Educational Institutes}

School administrators should have the capacity to be consistent with the PLC process, ie, the administrators should have a leadership and commitment to management. The key competencies should include: academic leadership, cooperative work, being a facilitator, coordinating relationships, promoting teachers' development and personnel, motivation, evaluation, promotion and supporting research and development and outreach technology Promotion. (Kiangsak, 2004). This was a significant role and performance in the development process. Development should include the following process: Structural improvement and community resource rehabilitation, professional learning $(\mathrm{P})$, following plan and supporting the professional learning community $(\mathrm{D})$, supervising and following the performance, (C) Management to promote the professional learning community, (A) To understand the relationship and good relationship between the community and leading to the result that was a continuation of quality culture through participation at all levels.

The results of questionnaire on problems and obstacles in professional community development found, in terms of problems and barriers to professional development, it was found that the school administrators had opinions on the problem as follows.

a. The key person was, there were no school management changes as suggested by 21 school personnel and most administrators lacked motivation for work in 20 schools and lacked creativity and lacked technology learning for 15 schools.

b. Participation was no network (PLC) with the team for 22 school administrators, no participatory action planning for 22 schools and lacked of problem analysis before implementation for 22 schools.

c. Academic was lack of information exchange on development. There was a lack of support for 24 school decisions, learning process of the learners with 24 schools, and lacked of training or instruction in assigned tasks and learning from a team of 24 schools.

d. The support (reinforcement) was lack of continuous monitoring of 24 schools, without a strong academic network. There were 24 external experts and there was no systematic collection and storage of data for database use to self-development and decision making for 24 schools.

\subsection{PLC Performance Development for School Administrators in Buriram Province}

The result for development of post-exchange management learning between school administrators, teachers and educational personnel, the results of the exchange for clear development in the PDCA format as follows. 
a. Plan, the start of the planned operation was planned. In the form of discussing issues to be developed. The initiator of the plan was the network leader to be responsible for coordinating the project in operational planning. Learning about problems and experiences and saw common problems or issues. If it was a PLC network, it would focus on the teacher's work and results directly to the students. It was very Important on leaders and network members for the concept of professional development in the professional community (PLC) was designed to be accurate and clear. Exchange management was beneficial to members of the network. This could lead to a more explicit exchange of ideas (Leithwood \& Riehl, 2003).

b. Do, the development of competency in teacher professional development in the professional community (PLC) resulted in school administrators, teachers and educational personnel knew knowledge and understood, had an innovative track or crystallization knowledge. It could be used for personnel with understanding and design a PLC collaboration system is tangible.

The process of exchanging learning to do AAR was the way that the executives brought the case to share the learning. Every member of the network expresses their opinions freely, opened up their minds and experiences for new things with the PLC group, which was an open-minded atmosphere and builds trust in the relationship of the group. As a result, a professional development partner could drive the PLC process in the school.

c. Check, this was a step that the school administrators, teachers and educational personnel was used to exchange ideas in the group process, which was used to reflect ideas after the knowledge sharing. It was important that the members of the exchange must be open minded and brave to report the actual results and that the executives should clearly summarize each issue.

d. Act, It was the process of bringing the results of exchanges in the PLC network group to adapt and enter new practice. It was a cycle that was constantly evolving around many circles and could be done without ending on the same subject. At the same time, there might be integration with other related issues because the PLC group had a positive attitude towards learning.

The key performance of the executive was the school administrator who should create an atmosphere to secure space to exchange learning together, honored in the difference between people and participation in systematic planning, monitoring, and reflection. The plan was based on participatory processes of personnel and stakeholders at all levels so that Successful factors in building the PLC community of the school (Southwest Educational Development Laboratory, 1997)

Administrators should have good attitude towards professional development activities in the professional community. They collaborated on every step of the PLC process, engaged in clear feedback from knowledge, ability and experiences (Brandt, 1995). It was an important part of creating an atmosphere of sharing learning among members. It had a commitment and attention to issues that solved problems and developed. It was the one who helped to increase and expand the knowledge of the PLC group.

\subsection{Model of PLC Process Improvement for School Administrators in Buriram Province}

After the training workshop, the researchers supervised the evaluation to study the model of PLC process improvement for school administrators in Buriram Province. The results showed that the development process was based on the PDCA model through the PLC process, with highly qualified consultants to use in the school in two forms as follows.

\subsection{Integrated Model of PDCA with mental intelligence by a Sub-PLC Group}

Integrated model of PDCA with mental intelligence through the PLC, the sub-process was characterized by the use of participatory processes through problem groups. The school administrators were Coaches.

a. Brainstorming to improve PLC Process Performance of Educational Institutions in Buriram Province.

Opening to brainstorm platform, grouping personnel, opening an opportunity for all stakeholders at all levels of education to bring problems to the meeting. Using common issues, jointing Requirements and urgent issues that needs to be resolved. The PLC could be classified as follows. a) administrators, teachers and educational personnel who taught in the same learning area, b) administrators, teachers, educational personnel who taught in the same classroom, c) administrators, teachers, educational personnel who had the same problems and d) administrators, teachers, educational personnel who supported the school mission.

b. Finding the problems and needs of all parties in the organization. Using participatory processes through card activity and offered verbally to share problems/needs, selected urgent priority issues and shared the learning to get the key problems, was urgent and high impact, fellow priority and impact of the problem by mutual consideration.

c. Participating to solve problems. 
1) Using a process of narrative, aesthetics discussion through the way of mental intelligence, telling experiences, sharing exchange to provide a variety of guideline and solutions to analyze together between groups and present to the members to learn as an open mind, believed and respect the differences between people and was confident in the relationship between the PLC group.

2) Groups and Members learned the success examples, good practice; patterns that were appropriate to the context of the institution and Included how to use the solution together and shared learning.

3) Participation in decision-making to choose a model, approach and innovation to solve the problems. The schools were suitable for their own context, was deep listening to the PLC group had reflected approach and model to their members could share their learning without prejudice. The observation was based on the principles and rational.

d. Designing of PLC problem-solving activities, brainstorming to find solutions and using logical analysis through the creation of ROAD MAP to solve common problems by the PLC group used participatory processes to design activities according to the method and chose the right innovation for the context of the school.

\section{e. Suggestion Exchange}

The PLC presented the model and activities to solve the problem which had the experts and experienced administrative consultants and was feedback through the nanny process (Coaching and Mentoring).

\section{f. Steps of Implementation}

School administrators were the most important people in driving the PLCs of schools by guiding to administer as follows:

1) Meeting leaders and staff to plan to drive PLC operations in schools.

2) Creating plans/projects for PLC operations.

3) Appointing PLC Operations Committee.

4) Designing activities and create a model driven PLC operations.

Group meeting to clarify knowledge and understanding groups to plan the implementation of the group. The use of mental intelligence as a tool. There were 3 times as follows:

1) 1st time 1) seeking problems/needs, 2) problems analysis/cause, logbook, 4) supervising and monitor for the 1 st time and 5) reporting the operation of PLC in school to the meeting.

2) 2nd time 1) Finding solutions, 2) logbook, 3) designing activities/ creating innovations in problem solving and supervision/innovations 4) logbook.

3) 3rd time 1) Conclusions the results of the model/method to solve the problem, 2) Discussion of the solution, suggestions for development, sharing learning through PLC sub-forums and 3) logbook.

g. Reflection

1) Conclusion of the model method for solving the problems.

2) Discuss the solution and suggestions for development.

\subsection{PLC Format for Specific Purposes}

PLC model for specific purposes had small PLC that needed to support from a school to solve problems for learning area with different contexts. It was very convenient and mobility in participation.

a. The school issued an ordinance and the board conducts PLC-level school processes.

b. Planning a PLC driven process into a school.

Teams of committees conducted PLC-driven school-level conferences, planning, formulating plans and activities as follows:

1) Providing the knowledge and understanding of the PLC process to every personnel in the school and making sure that the administrators developed a PLC knowledge sheet for all teachers to learn.

2) It required active training workshops to introduce active learning and PLC processes to the actual practice of teachers by inviting external speakers to conduct the knowledge.

3) It must be monitored, supervised and evaluated.

4) Encouraging, supporting and coordinating the development of teachers and educational personnel at all 
times.

c. The PLC process had defined the operating framework by assigning teachers to each learning area had productions at least each learning area for 2 work pieces.

d. Concluding and reporting.

The board conducted the PLC process, developed a plan and monitoring, supervising and evaluation tool.

The board conducted supervision and evaluation at the school level and then reported.

e. Exchanged activities, lesson learned, and honored PLC processors in PLC schools. The PLC process with logbook was reported individually to the school administrators. The board conducted to supervised, monitored and evaluated at school level. It summarized and reported the progress of monitoring the PLC process of the school to the school administrators to drive the PLC Process to schools that fitted School Context.

\subsection{Problems of PLC Development of Educational Institutes in Buriram Province}

a. Personally, the administrators did not change the administration of the school according to the recommendations of the personnel. Most administrators lacked motivation to work, creative thinking, technological learning, attention to personnel and members of the organization and Executives had high ego (not open mind), did not listen to the other opinions of their members in schools.

b. Participation was the school without a network. The PLC lacked engagement planning, problem analysis before implementation, opportunity for personnel to participate in learning to work with members of the organization and lacked of exchange and learning new things with fellow teachers.

c. Academic was lack of information exchange on development due to lack of supporting information for decision making. The learning process of learners with colleagues lacked effective training or mentor experiences.

d. Supporting was lack of continuous monitoring, no strong academic network. It was a system that was used by the external experts and lack of systematic collection and storage in self-development and decision making.

\subsection{Development of PLC Process Performance for School Administrators Buriram Province}

Administrators should have good attitude towards professional development activities in the professional community, collaborate on every step of the PLC process, and engage in clear feedback from knowledge, ability and experiences. It was an important part of creating an atmosphere of sharing learning among members, had a commitment and attention to issues that solve problems and developed. It was the one who helped to increase and expand the knowledge of the PLC group.

The key performance of the executive was the school administrators. They should create an atmosphere to secure space to exchange learning together, was honor in the difference between people and participation in systematic planning, monitoring, and reflection. The plan was based on participatory processes of personnel and stakeholders at all levels to the successful factors in building the PLC community in school.

\subsection{Model of PLC Process Improvement for School Administrators Buriram Province}

It could conclude on the model of PLC performance improvement for school administrators Buriram Province as follows:

Model 1. Integrated model of PDCA with mental intelligence by a sub PLC group

The PDCA was an integrated model of mental intelligence through the PLC, the sub-process was characterized by the use of participatory processes through problem groups, and the school administrator was a coach.

\section{Model 2. PLC Format for Specific Purposes}

It was a group of PLCs based on specific purposes. It was a small PLC that needed supporting from a school to solve problems at learning area level with different contexts. The effect was very convenient and mobility in participation.

It could summarize of PLC Processes of Buriram Educational Institutions. There was a common characteristic that was systematic planning and the participation of all stakeholders.

The successful factors of the PLC process for school administrators were as follows a) Understanding b) Mutual recognition c) Being ready to change attitudes d) Being open to new things e) Having clear knowledge in the process and in the matter. f) Administrators continually supported the team. g) Team understood the plan and participated in every step, and h) Leaders strived to have a clear goal for every process. 


\section{Discussion}

The school administrators understood and were aware of the role and importance of the PLC process were as follows:

a. The administrators and stakeholders should have knowledge, understand about professional development community (PLC) if it could not practice or did not understand. It might affected the success of the PLC process.

b. The administrators must open mind, understand, access and accept change when working with others to drive the professional development process in the form of PLC.

c. The problem and development issues or problem solving required planning to set the activities, steps and goals were clear.

\section{Suggestion}

a. It should have a research on the integration of PLC between government and private sector.

b. The research should be conducted to promote effective reinforcement models to drive the PLC process indifferent contexts of the school.

\section{References}

Brandt, R. (1995). On restructuring schools: A conversation with Fred Newmann. Educational Leadership, 53(3), 70-73.

Chaichaorat, R. (2015). The process of enhancing the ability to design instruction of trainee teacher according to the concept of professional learning community: Case Study Research (Thesis of Master of Education, Bangkok: Chulalongkorn University).

Hord, S. M., Roussin, J. L., \& Sommers, W. A. (2009). Guiding Professional Learning Communicaties Inspiration, Challenge, Surprise, and Meaning. London: Corwin.

Intanam, N., \& Wongwanich, S. (2014). An application of the professional learning community approach to developing the learning process and enhancing academic achievement in the mathematics and science teaching of the Primary School Student. Procedia-Social and Behavioral Sciences, 131, 476-483. https://doi.org/10.1016/j.sbspro.2014.04.151

Kiangsak, C. (December 1st, 2004). Strategy of Created Management Jobs. Daily Newspaper, 17(84), 62.

Leithwood, K. A., \& Riehl, C. (2003). What we know about successful school leadership. School Leadership \& Management Formerly School Organisation, 28(1), 27-42. https://doi.org/10.1080/13632430701800102

Luis, K. S., \& Kruse, S. D. (1995). Professional and community: Perspectives on reforming urban schools. Thousand Oaks, CA: Corwin Press

Lunenburg, F. C. (2010). Creating a professional learning community. National Forum of Educational Administration and Supervision Journal, 27(4), 1-7.

Southwest Educational Development Laboratory. (1997). Professional learning communities: What Are They and Why Are They Important? Issues About Change, 6(1), 1-4.

\section{Copyrights}

Copyright for this article is retained by the author(s), with first publication rights granted to the journal.

This is an open-access article distributed under the terms and conditions of the Creative Commons Attribution license (http://creativecommons.org/licenses/by/4.0/). 